\title{
Memorial strategy and rated imagery value in recognition and free recall*
}

\author{
DONALD ROBBINS $\dagger$, JAMES F. BRAY, and JAMES R. IRVIN \\ Emory University, Atlanta, Georgia 30322
}

\begin{abstract}
Two studies were conducted in which rated imagery value and memorial strategy instructions were manipulated. Experiment I was a forced-choice recognition study and Experiment II was a free-recall task. The results revealed significant rated imagery effects in both studies. Neither task resulted in significant instruction effects. However, in the free-recall task, when Ss were presented with pairs of words, more pairs appeared to be recalled for interactive in contrast to separation imagery instructions, although this difference was not statistically reliable.
\end{abstract}

Mental imagery has been shown to lead to very high levels of recall performance in paired-associate memory tasks (e.g., Paivio, 1969, 1971). In these studies when rated imagery (Paivio, Yuille, \& Madigan, 1968) is varied, Paivio (1969) has found that stimuli rated high in imagery yield better recall performance than stimuli rated low in imagery. Studies have also been conducted where Ss have been given specific instructions on how to memorize, using noun-noun pairs high in rated imagery. Substantially better recall performance has been found for Ss given interactive imagery instructions in contrast to those given rate repetition (Bower \& Winzenz, 1970; Paivio, 1971; Schnorr \& Atkinson, 1969) or separation imagery instructiois (Bower, 1970). Recently, Robbins, Bray, Irvin, and Wise (in press) found an interaction between rated imagery and memorial strategy in a paired-associate or a cued recall task. Specifically, they found superior performance for Ss given interactive imagery instructions only when the stimulus term was high in rated imagery. This interaction is expected by Paivio's (1971) conceptual peg hypothesis, since the linking together of the stimulus and response resulting from interacting imaginal codes is heightened by a stronger retrieval cue namely, a high-imagery stimulus term. The question arises whether this interaction between memorial strategy and rated imagery would occur in a recognition task or in a free recall task.

\section{EXPERIMENT I}

Gorman (1961) reported finding better recognition performance for high in contrast to low-rated imagery words. In addition, Bower (1970) failed to find any differences in stimulus recognition between groups of Ss given interactive imagery, separation imagery or rote repetition instructions, although differences in recall performance, as noted previously, were found for the

*This research was supported in part by Grant MH20331 from the National Institute of Mental Health and in part by a grant from the Emory University Graduate School of Arts of Sciences. tRequests for reprints should be sent to: Donald Robbins, Department of Psychology, Emory University, Atlanta, Georgia 30322 . high-imagery noun pairs he used. Bower (1970) used only noun pairs of high rated imagery. In this study we manipulated both instructions and rated imagery value.

\section{Method}

Subjects. Twenty-four Ss were obtained from the introductory psychology $\mathrm{S}$ pool and partially fulfilled a course requirement by participating in a 15-20-min session.

Procedure. The Ss were tested in small groups of up to five people. These small groups were randomly assigned to one of two groups $(\mathrm{N}=12)$ and were instructed to memorize noun-noun pairs by using either interactive imagery (Group II) or separation imagery (Group SI) instructions (after Bower, 1970). One study trial of 46 noun pairs was used, one word was at the top and the other word on the bottom of a slide. One member of each pair was high in rated imagery (mean value on the Paivio et al, 1968 norms of 6.56) while the other member was low in rated imagery (mean of 2.31), i.e., HL or LH pairs. In addition, the words of each pair were equated on Thorndike and Lorge (1944) frequency. Half of the pairs were high frequency (20 or more) and the remaining half were low frequency (1-4). Thus, the stimulus pairs represented a factorial combination of rated imagery (high or low) and Thorndike-Lorge frequency (high or low) as shown in Table 1. On the study trial the pairs were presented at a 6-sec rate with a Kodak Carousel projector, and the Ss were told that they would later be tested for memory of the words. The first three pairs (primary buffer) and the last three pairs (recency buffer) were not tested. After the presentation of the list, Ss were given a two-alternative forced-choice test. They were given a list of 80 noun-noun pairs and were told that one member of each pair was an "old" word and to circle the word they thought was old. Each input word was paired with a "new" word of equal rated imagery and Thorndike-Lorge frequency. In addition, each small group of Ss was given the study and test lists in a different random order, and the particular cue pairings used during testing were changed for each subgroup.

\section{Results and Discussion}

The results are shown in Table 1 and reveal no difference due to instruction, $F<1$. However, there were more recognition errors for low imagery words in contrast to high imagery words, $F(1,22)=17.77$, $\mathrm{p}<.001$, while none of the interactions were significant, Fs $<1$. Specifically, the proportion of old words recognized as old was .96 and .88 for rated high and low imagery, respectively. Although the effect may be smaller than one might expect, these data, using HL 
Table 1

Mean Recognition (Experiment I) and Free Recall (Experiment II) Performance

\begin{tabular}{|c|c|c|c|c|c|c|c|}
\hline & & \multicolumn{2}{|c|}{$\begin{array}{c}\text { Free Recall } \\
\text { Mean Number Recalled } \\
\text { Frequency }\end{array}$} & \multirow[b]{2}{*}{ Total } & \multicolumn{2}{|c|}{$\begin{array}{c}\text { Recognition } \\
\text { Mean Number of Errors } \\
\text { Frequency }\end{array}$} & \multirow[b]{2}{*}{ Total } \\
\hline & & High & Low & & High & Low & \\
\hline $\begin{array}{l}\text { Group II } \\
\text { Imagery }\end{array}$ & $\begin{array}{l}\text { High } \\
\text { Low } \\
\text { Total }\end{array}$ & $\begin{array}{l}4.33 \\
3.00 \\
7.33\end{array}$ & $\begin{array}{l}4.20 \\
3.20 \\
7.40\end{array}$ & $\begin{array}{r}8.53 \\
6.20 \\
14.73\end{array}$ & $\begin{array}{l}1.17 \\
2.92 \\
4.09\end{array}$ & $\begin{array}{l}0.42 \\
2.00 \\
2.42\end{array}$ & $\begin{array}{l}1.59 \\
4.92 \\
6.51\end{array}$ \\
\hline $\begin{array}{l}\text { Group SI } \\
\text { Imagery }\end{array}$ & $\begin{array}{l}\text { High } \\
\text { Low } \\
\text { Total } \\
\end{array}$ & $\begin{array}{l}4.47 \\
3.07 \\
7.54 \\
\end{array}$ & $\begin{array}{l}3.73 \\
3.07 \\
6.80\end{array}$ & $\begin{array}{r}8.20 \\
6.14 \\
14.34 \\
\end{array}$ & $\begin{array}{l}1.00 \\
2.92 \\
3.92\end{array}$ & $\begin{array}{l}0.92 \\
1.83 \\
2.75\end{array}$ & $\begin{array}{l}1.92 \\
4.75 \\
6.67\end{array}$ \\
\hline
\end{tabular}

pairs, replicate those of Bower (1970) who used HH pairs. Thus, no interaction was found since instructions did not affect recognition, although rated imagery did. These results seem to be consistent with Paivio's (1971) conceptual peg hypothesis if it is assumed that linking the word pair together would not enhance recognition of the individual members. It is also interesting to note that more recognition errors were found for high frequency in contrast to low frequency words, $F(1,22)=7.43$, $p<.025$. This confirms previous findings of this effect (e.g., Gorman, 1961). Also, as shown in Table 1, the frequency effect did not interact with that resulting from rated imagery value, $\mathrm{F}<1$ (Gorman, 1961).

\section{EXPERIMENT II}

This study is concerned with a free recall task. When Ss are presented a list of words varying in rated imagery, more words high in rated imagery are recalled than words low in rated imagery (Dukes \& Bastian, 1966; Tulving, McNulty, \& Ozier, 1965; Winnic \& Kressel, 1965). Further, Mueller and Jablonski (1970) also found that imagery instructions led to better performance than a standard free recall group. However, they told their Ss to link one or more items together. Hence, if Ss link words together in a free recall task or are given pairs of words and then tested for recall, instructions may significantly affect performance. In this study, Ss were presented with pairs of words and given interactive or separation imagery instructions and then tested for free recall of all of the words.

\section{Method}

Subjects. Thirty Ss were obtained from the introductory psychology $S$ pool and partially fulfilled a course requirement by participating in a 15-20-min session. None of these Ss had participated in Experiment I.

Procedure. The procedure was identical to that of Experiment I except for the method of testing. Briefly, 46 word pairs were presented at a 6 -sec rate. One member of each pair was high in rated imagery while the other was low in rated imagery. The words pairs represented a factorial combination of rated imagery (high or low) and Thorndike-Lorge frequency (high or low). The Ss were run in small groups of up to five and these small groups were randomly assigned to. either an interactive (Group II) or separation imagery (Group SI) instruction group ( $\mathrm{N}=15$ per group). The three primacy and recency buffer pairs were not included in the analysis. After the presentation of the list, the Ss were given a 5 -min free recall period.

\section{Results and Discussion}

The results are shown in Table 1 and indicate that there was no instruction effect, $\mathrm{F}<1$. However, more high imagery words were recalled than low-imagery words, $F(1,28)=44.05, p<.001$. Further, there was no effect due to frequency nor were any of the interactions significant, $F s<1$. In addition, although the interactive imagery group recalled more pairs than the separation group, a mean of 5.07 as contrasted with 3.80 , respectively, this difference was not statistically significant, $F(1,28)=1.42, p>.05$. Further, the total numbers of words recalled was not significantly different, 14.73 vs 14.34 for Groups II and SI, respectively, $F<1$. The failure to find a significant difference between instruction conditions in the number of word pairs recalled may be a result of relatively high variability, since the mean difference was approximately $30 \%$.

\section{CONCLUSIONS}

These studies have failed to reveal an interaction between memorial strategies and rated imagery values in a forced-choice recognition task and a free recall task. In both studies rated imagery affected performance. However, when two words were presented at one time to Ss in a free recall task, more of these pairs appeared to be recalled for Ss given interactive imagery in contrast to separation imagery instructions, although this difference was not statistically reliable. These data lend further support to the assumption (Paivio, 1971) that the improved performance resulting from linking words together is enhanced when a relatively strong retrieval cue is provided (i.e., one high in rated imagery).

\section{REFERENCES}

Bower, G. H. Imagery as a relational organizer in associative learning. Journal of Verbal Learning \& Verbal Behavior, 1970, 9, 529-533.

Bower, G. H., \& Winzenz, D. Comparison of associative learning strategies. Psychonomic Science, 1970, 20, 119-120.

Dukes, W. F., \& Bastian, J. Recall of abstract and concrete words equated on meaningfulness. Journal of Verbal Learning \& Verbal Behavior, 1966, 5, 455-458.

Gorman, A. M. Recognition memory for nouns as a function of abstractness and frequency. Journal of Experimental Psychology, 1961, 61, 23-29.

Mueller, T. H., \& Jablonski, E. M. Instructions, noun imagery, and priority in free recall. Psychological Reports, 1970, 27, 559-566. 
Paivio, A. Mental imagery in associative learning and memory. Psy chological Review, 1969, 76, 241-263.

Paivio, A. Imagery and verbal processes. New York: Holt, Rinehart, \& Winston, 1971

Paivio, A., Yuille, J. C., \& Madigan, S. Concreteness, imagery, and meaningfulness values for 925 nous. Journal of Experimental Psychology Monograph Supplement, 1968, 76, (1, Pt. 2).

Robbins, D., Bray, J. F., Irvin, J. R., \& Wise, P. R. Memorial strategy and imagery: An interaction between instructions and rated imagery. Journal of Experimental Psychology, in press. Schnorr, J. A., \& Atkinson, R. C. Repetition versus imagery instructions in the short-term and long-term retention of paired-associates. Psychonomic Science, 1969, 15, 183-184.
Thorndike, E. L., \& Lorge, J. The teacher's wordbook of 30,000 words. New York: Teachers College, Columbia University, 1944.

Tulving, E., McNulty, J. A., \& Ozier, M. Vividness of words and learning to learn in free-recall learning. Canadian Journal of Psychology, 1965, 19, 242-252.

Winnick, W. A., \& Kressel, K. Tachistoscopic recognition thresholds, paired-associate learning and immediate recall as a function of abstractness-concreteness and word frequency. Journal of Experim ental Psychology, 1965, 70, 163-168.

\title{
High-speed memory scan as a retention interval activity in short-term memory*
}

\author{
DAVID S. GORFEIN \\ New College, Sarasota, Florida 33578
}

\begin{abstract}
A Sternberg high-speed memory scan task was used as a retention interval activity in a standard Brown-Peterson paradigm. Two levels of Sternberg search set, one or five items, were employed to see if the differential memory load produced by the different size search sets resulted in differential recall in the Brown-Peterson task. A comparison was made to a control condition in which $\mathrm{S}$ was required to shadow digits during the retention interval. No differential effect on recall of memory load was found when the Sternberg tasks were compared across three different retention intervals. Very little forgetting was produced by the Sternberg tasks as compared to the digit shadowing condition. Results are discussed in terms of the need for verbal activity to prevent rehearsal in short-term memory.
\end{abstract}

Researchers in memory have frequently adopted the technique of varying the retention interval activity in an attempt to explicate the storage and rehearsal process. In short-term memory (STM) utilizing the Brown-Peterson paradigm (Brown, 1958; Peterson \& Peterson, 1959), dependence of recall on the retention interval activity has been well demonstrated. Posner and Rossman (1965) have varied information processing in the retention interval while Loess and McBurney (1965) have also shown effects of the difficulty of the retention interval task. Such manipulations, however, provide no theoretical basis for understanding the amount of interference obtained. There is no basis for determining how the interfering activity interacts with items in storage. Many of the modern conceptions of information processing, e.g., Atkinson and Shiffrin (1968), postulate a limited capacity working memory which can only process items for long-term storage insofar as the capacity of working memory (generally shown to be in the range from 1 to 5 items) is not exceeded. We have no way of determining whether such variables as amount of information reduced (Posner, 1964) influences time alone (S may take longer to do a more difficult information processing task), working memory capacity (it may take more capacity to do the more difficult tasks), or some combination of time and capacity. The

*This research was supported by Public Health Service Grant MH 19799-01. problem is essentially that we have no direct way of measuring the amount of working memory capacity utilized for the tasks traditionally used as retention interval activities.

Sternberg $(1966,1967)$ has presented evidence that these parameters (memory load and processing time) may be specifiable for a type of memory search task. In this task $\mathrm{S}$ first learns a set of digits (the set size can be varied from task to task). S's retention of the digit is tested by a probe recognition task in which the $S$ in instructed to press one of two keys to indicate that, yes, the probe was a member of the to-be-remembered set, or, no, the probe item was not a member of the to-be-remembered set. Reaction time data is recorded. By analysis of the reaction time data, Sternberg shows that this paradigm is comparable to an analogous paradigm in short-term memory where a new to-be-remembered set is presented just prior to each probe. The data show an exhaustive search of the to-be-remembered set. Sternberg argues cogently that this indicates that the search set is transferred to working memory and then searched exhaustively (his argument is based on the identical slope of reaction time as a function of the size of search set to that in the short-term high-speed scan paradigm but an increase in intercept in the long-term paradigm). The Sternberg paradigm therefore provides the desirable features of allowing us to measure directly the time taken by the task and the amount of capacity occupied by the task 